\title{
Carbanions. 3. Nuclear Magnetic Resonance Spectroscopic and Theoretical Study of Homoaromaticity in Cyclohexadienyl Anions ${ }^{1}$
}

\author{
George A. Olah, ${ }^{* 2 a}$ Gregorio Asensio, ${ }^{2 b}$ Herbert Mayr, ${ }^{* 2 b, c}$ and P. v. R. Schleyer ${ }^{2 c}$ \\ Contribution from the Hydrocarbon Institute, Department of Chemistry, \\ University of Southern California, Los Angeles, California 90007, and the \\ Institut für Organische Chemie der Universität Erlangen-Nürnberg. \\ 8520 Erlangen, West Germany. Received December 14, 1977
}

\begin{abstract}
By analogy with the homocyclopropenyl (1) and homotropylium cations (2), cyclohexadienyl anions (3) might also be expected to be nonplanar, homoaromatic species. Several such anions, prepared by proton abstraction from the corresponding 1,3- and 1,4-cyclohexadienes, were studied by ${ }^{1} \mathrm{H}$ and ${ }^{13} \mathrm{C}$ NMR spectroscopy in $\mathrm{ND}_{3}$ solution. Interpretation of the chemical shifts, coupling constants, and the results of low-temperature studies at $300\left({ }^{1} \mathrm{H} \mathrm{NMR}\right)$ and $67.88 \mathrm{MHz}\left({ }^{13} \mathrm{C} \mathrm{NMR}\right)$ indicated these cyclohexadienyl anions rather to be planar nonhomoaromatic species. MINDO/3 calculations on the parent cyclohexadienyl anion agreed; the planar form was found to be a shallow energy minimum. The large spatial separation between the $\pi$-system termini and the stabilizing interaction of $\pi^{*}\left(\mathrm{CH}_{2}\right)$ with the HOMO of the pentadienyl fragment are responsible for the absence of the expected homoaromaticity.
\end{abstract}

The possibility that a cyclic Hückeloid array of $(4 n+2)$ $\pi$ electrons might be interrupted in one or more positions by an intervening saturated linkage and still retain a significant amount of aromatic delocalization energy was first suggested by Applequist and Roberts in $1956.3 \mathrm{a}$ This concept, which Winstein generalized and termed "homoaromaticity", is now familiar and has been extensively reviewed. ${ }^{3 \mathrm{~b}-\mathrm{d}}$ Experimental studies of monocyclic homoaromatic ions have dealt mainly with the $2 \pi$ homocyclopropenium $(1)^{4}$ and the $6 \pi$ homotropylium cations (2). ${ }^{5}$ Both parent ions prefer nonplanar struc-

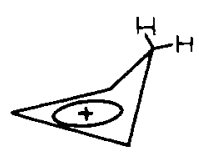

$\stackrel{1}{=}$

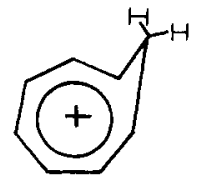

$\stackrel{2}{=}$

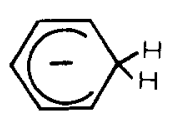

$\stackrel{3 a}{\underline{a}}$

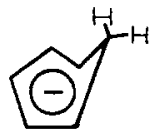

$\underline{\underline{3 b}}$ tures. ${ }^{6}$ In contrast, remarkably little attention has been paid to the intervening system, the cyclohexadienyl (3a) or homocyclopentadienyl anion (3b).

Kloosterziel and van Drunen studied a series of cyclic dienyl anions by ' $\mathrm{H}$ NMR spectroscopy and concluded that no ring current occurs in $\mathbf{3}$ unless there is an accidental cancellation due to more than one effect ${ }^{7}$ working in the opposite direction. In a ${ }^{13} \mathrm{C}$ NMR study of dienyl anions no evidence for the homoaromaticity of $\mathbf{8}$ was detected. ${ }^{8}$ In contrast, several theoretical studies of homoaromaticity have concluded that 3 should be considered to be the homocyclopentadienyl anion (3b). ${ }^{9}$ Because of the discrepancy between experimental and theoretical conclusions, we have reexamined the nature of 3 by both methods.

\section{Experimental Results}

Clear, red solutions of the cyclohexadienyl anions 3,6 , and 8 and the cycloheptadienyl anion (9) were obtained by proton abstraction from the corresponding 1,3- or 1,4-dienes with potassium amide in liquid ammonia at $-60^{\circ} \mathrm{C}$. Treating 1methyl-1,4-cyclohexadiene (10) with $\mathrm{KNH}_{2}$ under the same conditions yielded a mixture of 1-methylcyclohexadienyl (11) and of 2-methylcyclohexadienyl anions (12) along with toluene, in molar ratios of $1.5: 2.5: 1.0$, respectively. The solutions of the anions could be stored at $-78{ }^{\circ} \mathrm{C}$ for several days without noticeable decomposition. At $-40^{\circ} \mathrm{C}$ decomposition of $\mathbf{3}$ into benzene, and of $\mathbf{1 1}$ and $\mathbf{1 2}$ into toluene, was observed.
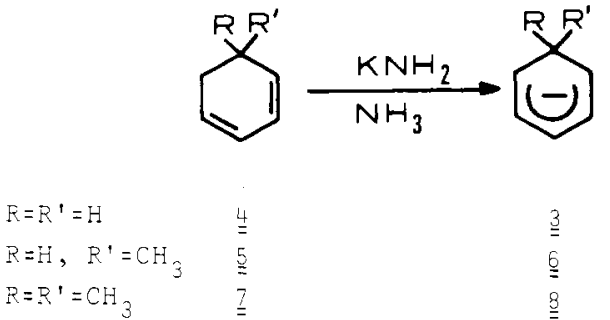

$$
\begin{aligned}
& \underline{4} \\
& \underline{5} \\
& \stackrel{7}{=}
\end{aligned}
$$

$\stackrel{3}{=}$
$\underline{6}$
$\underline{9}$

Anion 8, as previously reported, ${ }^{8}$ was stable in THF solution even at room temperature. The NMR spectroscopic data of the anions and their precursors are collected in Tables I and II. The observed equivalence of the methylene protons in $\mathbf{3}$ is in accord either with a planar structure or with two rapidly equilibrating puckered species, $\mathbf{3 b}$ and $\mathbf{3}^{\prime}$. If the latter were

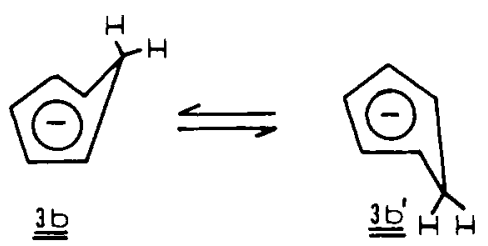

the case, it might be possible to freeze out the puckered forms on the NMR time scale either by lowering the temperature or by increasing the magnetic field strength. The lowest temperature accessible with a solution of 3 in $\mathrm{ND}_{3}$ was $-60^{\circ} \mathrm{C}$ (freezing point of the solvent). At this temperature broadening of the $\mathrm{CH}_{2}$ signal caused by nonequivalence of the two protons could not be detected, even at $300 \mathrm{MHz}$. If it is assumed that the chemical shift difference of the methylene protons in the hypothetical puckered homocyclopentadienyl anion should be at least as large as in the cyclobutenyl cation ( $\delta$ is much larger in the homotropylium ion), the maximum barrier for the ring flipping process would be $8 \mathrm{kcal} / \mathrm{mol} .{ }^{4}$ Furthermore, the $67.88-\mathrm{MHz}{ }^{13} \mathrm{C}$ NMR spectrum of 8 at $-120^{\circ} \mathrm{C}$ (THF/DME solution) did not show nonequivalence of the methyl carbons. Since ${ }^{13} \mathrm{C}$ chemical shift differences are generally larger than ' $\mathrm{H}$ shift differences, a much lower barrier, if not a planar structure, is indicated by this observation.

\section{${ }^{13} \mathrm{C}$ NMR Chemical Shifts}

Indirect evidence for the planar structure of $\mathbf{3}$ can be obtained from ${ }^{13} \mathrm{C}$ chemical shifts, which have been found to be proportional to $\pi$-electron densities in cyclic aromatic sys- 
Table I. ${ }^{13} \mathrm{C}$ NMR Chemical Shifts ${ }^{a}$ and $J_{\mathrm{CH}}$ Values ${ }^{b}$ for Anions ${ }^{c}$ and Their Precursors

\begin{tabular}{|c|c|c|c|c|c|c|c|}
\hline $\begin{array}{c}\begin{array}{c}\text { Diene or } \\
\text { anion }\end{array} \\
\end{array}$ & $C_{1}$ & $\mathrm{C}_{2}$ & $\mathrm{C}_{3}$ & $\mathrm{C}_{4}$ & $\mathrm{C}_{5}$ & $\mathrm{C}_{6}$ & $C_{7}$ \\
\hline 3 & $(147.0 \mathrm{~d})$ & $\frac{.8}{(142.0 \mathrm{~d})}$ & $\begin{array}{c}78.0 \\
(154.5 \mathrm{~d})\end{array}$ & $\begin{array}{l}131.8 \\
(142.0 \mathrm{~d})\end{array}$ & $\begin{array}{c}75.8 \\
(147.0 \mathrm{~d})\end{array}$ & $\begin{array}{c}30.0 \\
(123.7 t)\end{array}$ & \\
\hline 4 & 126.1 & 124.8 & 124.8 & 126.1 & 22.6 & 22.6 & \\
\hline 5 & 133.0 & 123.9 & 124.5 & 125.6 & 31.3 & $\begin{array}{c}28.5 \\
(125 \mathrm{t})\end{array}$ & 20.2 \\
\hline 6 & $\begin{array}{c}86.2 \\
(152.4 \mathrm{~d})\end{array}$ & $\begin{array}{l}129.1 \\
(143.3 \mathrm{~d})\end{array}$ & $\begin{array}{c}77.5 \\
(156.9 \mathrm{~d})\end{array}$ & $\begin{array}{c}129.1 \\
(143.3 \mathrm{~d})\end{array}$ & $\begin{array}{c}86.2 \\
(152.4 \mathrm{~d})\end{array}$ & $\begin{array}{c}34.0 \\
(116.2 \mathrm{~d})\end{array}$ & $\begin{array}{c}26.7 \\
(122.5 q)\end{array}$ \\
\hline 7 & 137.7 & 122.4 & 123.7 & 125.3 & 38.4 & 31.1 & 28.3 \\
\hline $8^{e}$ & $\begin{array}{c}90.9 \\
(150.9 \mathrm{~d})\end{array}$ & $\begin{array}{l}127.0 \\
(141.2 \mathrm{~d})\end{array}$ & $\begin{array}{c}78.0 \\
(155.5 \mathrm{~d})\end{array}$ & $\begin{array}{l}127.0 \\
(141.2 \mathrm{~d})\end{array}$ & $\begin{array}{c}90.9 \\
(150.9 \mathrm{~d})\end{array}$ & 33.5 & $\begin{array}{c}32.9 \\
(122.9 \mathrm{q})\end{array}$ \\
\hline 9 & $\begin{array}{c}93.0 \\
(150 \mathrm{~d})\end{array}$ & $\begin{array}{c}133.8 \\
(136 d)\end{array}$ & $\begin{array}{c}77.3 \\
(148 \mathrm{~d})\end{array}$ & $\begin{array}{l}133.8 \\
(136 \mathrm{~d})\end{array}$ & $\begin{array}{c}93.0 \\
(150 \mathrm{~d})\end{array}$ & 36.6 & 36.6 \\
\hline 10 & 131.1 & 119.1 & $\begin{array}{c}27.3 \\
(123.0 \mathrm{t})\end{array}$ & 124.4 & 124.4 & $\begin{array}{c}31.0 \\
(125.0 \mathrm{t})\end{array}$ & 23.4 \\
\hline 11 & 89.8 & $\begin{array}{c}127.8 \\
(140 \mathrm{~d})\end{array}$ & $\begin{array}{c}79.5 \\
(156 \mathrm{~d})\end{array}$ & $\begin{array}{l}131.5 \\
(140 \mathrm{~d})\end{array}$ & $\begin{array}{c}70.7 \\
(146 d)\end{array}$ & $\begin{array}{c}35.1 \\
(122 \mathrm{t})\end{array}$ & $\begin{array}{c}25.6 \\
(121 \mathrm{q})\end{array}$ \\
\hline 12 & $\begin{array}{c}77.7^{d} \\
(150.3 \mathrm{~d})\end{array}$ & 139.9 & $\begin{array}{c}77.1^{d} \\
(150.3 d)\end{array}$ & $\begin{array}{l}132.6 \\
(141.7 d)\end{array}$ & $\begin{array}{c}77.9^{d} \\
(150.3 \mathrm{~d})\end{array}$ & $\begin{array}{c}31.4 \\
(125 t)\end{array}$ & $\begin{array}{c}22.5 \\
(122 q)\end{array}$ \\
\hline & 124.1 & 124.1 & $\begin{array}{c}25.7 \\
(126.0 \mathrm{t})\end{array}$ & 124.1 & 124.1 & 25.7 & \\
\hline
\end{tabular}

${ }^{a}$ Carbon chemical shifts are relative to external (capillary) $\mathrm{Me}_{4} \mathrm{Si} .{ }^{b}$ Coupling constants $(\mathrm{Hz})$ are given in parentheses. $c$ In ammonia solution at $-60^{\circ} \mathrm{C}$ as $\mathrm{K}^{+}$salts. ${ }^{d}$ Relative assignment uncertain. ${ }^{e}$ Similar values are reported in ref 8 a for the $\mathrm{Li}^{+}$salt in THF solution.

Table II. ${ }^{1} \mathrm{H}$ NMR Chemical Shifts ${ }^{a}$ and $J_{\mathrm{HH}}$ Values $^{b}$ for Cyclohexadienyl Anions ${ }^{c}$ and Their Precursors

\begin{tabular}{|c|c|c|c|c|c|c|c|c|}
\hline $\begin{array}{c}\text { Anion or } \\
\text { diene }\end{array}$ & $\mathrm{H}_{1}$ & $\mathrm{H}_{2}$ & $\mathrm{H}_{3}$ & $\mathrm{H}_{4}$ & $\mathrm{H}_{5}$ & $\mathrm{H}_{6}$ & $\mathrm{H}_{7}$ & $\begin{array}{l}J_{\mathrm{HH}} \text { coupling } \\
\text { constants, } \mathrm{Hz}\end{array}$ \\
\hline $3^{d}$ & $3.3, d$ & $5.9, \mathrm{dd}$ & $3.7, \mathrm{t}$ & $5.9, \mathrm{dd}$ & $3.3, \mathrm{~d}$ & 3.4 & & $J_{12}=7.5 ; J_{23}=6.0$ \\
\hline 5 & $5.7, \mathrm{~m}$ & $5.7, \mathrm{~m}$ & $5.7, \mathrm{~m}$ & $5.7, \mathrm{~m}$ & $2.1, \mathrm{~m}$ & 2.4 & 1.0 & \\
\hline 6 & $3.5, \mathrm{~d}$ & $6.0, \mathrm{dd}$ & $3.8, \mathrm{t}$ & $6.0, \mathrm{dd}$ & $3.5, \mathrm{~d}$ & 3.5 & 0.9 & $J_{12}=7.8 ; J_{23}=6.5$ \\
\hline 7 & $5.3-5.9, \mathrm{~m}$ & $5.3-5.9, \mathrm{~m}$ & $5.3-5.9, \mathrm{~m}$ & $5.3-5.9, \mathrm{~m}$ & $2.1, \mathrm{~d}$ & & 1.0 & \\
\hline $8^{e}$ & $3.6, \mathrm{dd}$ & $6.1, \mathrm{dd}$ & $3.9, \mathrm{t}$ & $6.1, \mathrm{dd}$ & 3.6. dd & & 1.0 & $\begin{array}{c}J_{12}=7.5 ; J_{23}=6 \\
\quad J_{13}=1\end{array}$ \\
\hline 10 & & 5.3 & 2.5 & 5.6 & 5.6 & 2.5 & 1.5 & \\
\hline 11 & & $5.6, d$ & $3.3-3.6$ & $5.9, \mathrm{t}$ & $3.3-3.6$ & 4.0 & 1.6 & $J_{23}=5.5 ; J_{45}=7.5$ \\
\hline 12 & $3.3-3.6$ & & $3.3, \mathrm{~d}$ & $6.0, \mathrm{t}$ & $3.3-3.6$ & 3.6 & 1.8 & $J_{34}=6: J_{45}=8$ \\
\hline
\end{tabular}

a Hydrogen chemical shifts are relative to external (capillary) $\mathrm{Me}_{4} \mathrm{Si} .{ }^{b}$ Coupling constants are in hertz. ${ }^{\circ}$ In $\mathrm{ND}_{3}$ at $-60^{\circ} \mathrm{C}$ as $\mathrm{K}^{+}$salts. d Similar values are reported in ref $7 .{ }^{e}$ Similar values are reported for the $\mathrm{Li}^{+}$salt in ref $8 \mathrm{~b}$.

tems. ${ }^{11}$ The proportionality constant is approximately 160 $\mathrm{ppm} /$ electron. More recently it was shown that this linear shift relationship can be more widely applied to $\mathrm{sp}^{2}$-hybridized carbons in planar, conjugated systems. ${ }^{12}$

In alternating $\pi$-delocalized ions the charge is localized at the odd-numbered carbons, whereas the even-numbered carbons remain almost uncharged. This prediction of MO theory is reflected by the ${ }^{13} \mathrm{C}$ NMR chemical shifts. In ordinary conjugated carbenium ions and carbanions the chemical shifts of the even-numbered carbons are about the same as the ${ }^{13} \mathrm{C}$ NMR shifts of neutral olefins. In contrast, the odd-numbered carbons are shifted significantly: upfield in carbanions $(\mathbf{1 3}, \mathbf{1 4})$, downfield in carbenium ions $(\mathbf{1 5}, \mathbf{1 6})$.

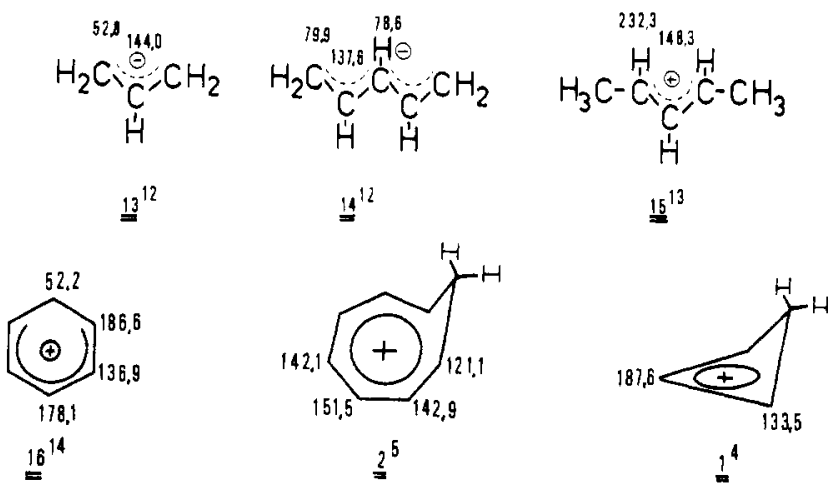

The situation is quite different in the homoaromatic ions, 1 and 2 . According to the ${ }^{13} \mathrm{C}$ NMR chemical shifts, the charge is now distributed over all olefinic carbon atoms. The terminal carbon atoms experience an upfield shift due to a decrease of positive charge and a partial conversion from $\mathrm{sp}^{2}$ to $\mathrm{sp}^{3}$ hybridization.

The ${ }^{13} \mathrm{C}$ NMR chemical shifts of the cyclohexadienyl anion show that 3 behaves as a typical pentadienyl anion. C-2 and C-4 do not carry negative charge, as demonstrated by the similarity of their chemical shifts to those of the corresponding cation, 16. The total upfield shift for $C-1$ to $C-5$ relative to benzene $(\delta 128.7)$ is $-151.5 \mathrm{ppm}$, approximately that expected for the location of one additional electron on these atoms. ${ }^{12}$ Because of the large C-1-C-5 distance a significant amount of 1,5 overlap cannot be present in the cycloheptadienyl anion (9). Since $\delta \mathrm{C}-2(\mathrm{C}-4)$ and $\delta \mathrm{C}-3$ are almost identical in 3 and

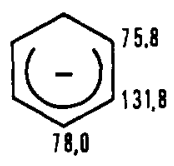

$\stackrel{3}{=}$

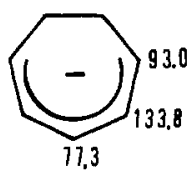

s
9, it must also be concluded that homoaromaticity is absent in the cyclohexadienyl anion (3). The different $\mathrm{C}-1$ shieldings in 3 and 9 are caused by the different surroundings of these atoms. 
The sensitivity of the $C-1$ shieldings toward substitution at C-6 is also demonstrated in the series 3,6 , and 8 (Table I); $\delta$ $\mathrm{C}-3$ remains unchanged (indicating absence of charge redistribution) while $\delta \mathrm{C}-1$ exhibits a $15-\mathrm{ppm}$ upfield shift. The relative shieldings of $\mathrm{C}-1$ and $\mathrm{C}-3$ are reversed from 3 to 8 , which indicates that the ${ }^{13} \mathrm{C}$ shieldings in this series are not solely determined by $\pi$-charge densities. It is not possible, therefore, to rationalize the experimentally observed C-3 protonation of cyclohexadienyl anions on the basis of their ${ }^{13} \mathrm{C}$ shieldings, as has previously been attempted. ${ }^{8}$

Methyl substitution of the pentadienyl framework of $\mathbf{3}$ does not alter the charge distribution significantly (11 and 12). The<smiles>Cc1ccccc1</smiles>

$\underline{11}$<smiles>Cc1ccccc1</smiles>

$\underline{12}$ 5-ppm upfield shift of C-5 in 11 (compared with $\mathbf{3}$ ) indicates $\pi$-electron repulsion by the methyl group. Similar $\pi$-electron donation effects have been observed in the ${ }^{13} \mathrm{C}$ NMR spectra of methyl-substituted allyl cations. ${ }^{15}$

\section{${ }^{13} \mathrm{C}-{ }^{1} \mathrm{H}$ Coupling Constants}

Couplings between ${ }^{13} \mathrm{C}$ and ${ }^{1} \mathrm{H}$ nuclei are very sensitive to angular distortion, as is shown by ${ }^{1} J_{\mathrm{CH}}=125 \mathrm{~Hz}$ in cyclohexane, $136 \mathrm{~Hz}$ in cyclobutane, and $161 \mathrm{~Hz}$ in cyclopropane. ${ }^{11 \mathrm{~b}}$ Therefore, these coupling constants are an additional tool for detecting homoaromatic overlap, as demonstrated by the following two examples. The planar unstrained mesitylenium ion

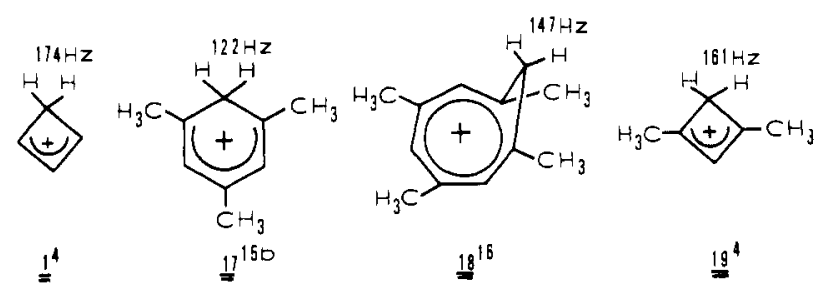

(17) shows a ${ }^{1} J_{\mathrm{CH}}=122 \mathrm{~Hz}$ whereas the corresponding methylene coupling in the tetramethylhomotropylium ion (18) increases to $147 \mathrm{~Hz}$ because of angular strain. From ${ }^{13} \mathrm{C}$ NMR chemical shifts and from the different temperature dependence of the ${ }^{1} \mathrm{H}$ NMR spectra ${ }^{4}$ as well as from MINDO/ 3 calculations ${ }^{19}$ it has been concluded that puckering is more important in 1 than in 19 . In agreement with this interpretation, ${ }^{1} J_{\mathrm{CH}}$ of the $\mathrm{CH}_{2}$ group increases from $161 \mathrm{~Hz}$ in 19 to $174 \mathrm{~Hz}$ in 1 .

In the cyclohexadienyl anion (3) ${ }^{1} J_{\mathrm{C}^{6} \mathrm{H}}$ was found to be 124 $\mathrm{Hz}$, a typical value for $\mathrm{sp}^{3}$-hybridized carbon atoms in the absence of angle strain. The agreement of this value with the corresponding coupling in 1,4-cyclohexadiene $(126 \mathrm{~Hz})$ and in the benzenium ion $17(122 \mathrm{~Hz})$ further indicates the absence of puckering and consequent 1,5 overlap in 3 .

\section{Calculations and Discussion}

Since both the $2 \pi$-homocyclopropenylium ion 1 and the $6 \pi$-homotropylium ion 2 possess nonplanar structures, the experimentally indicated planar conformation of 3 would seem to be an unexpected exception. Can ring strain account for the different geometries of 1,2 , and 3 ? Enhancement of homoaromatic overlap by puckering implies partial formation of three-membered rings, i.e., partial formation of bicyclic from monocyclic species. Table III provides an estimate of the relative strain increase in the three systems, provided that formation of the bicycle were complete. ${ }^{17} \mathrm{~A}$ larger increase of strain is observed in the rings with $n=1$ and $n=3$ than in the open-chain reference system. In contrast, less strain is gener-
Table III. Hydrocarbon Strain Energies, $\mathrm{kcal} / \mathrm{mol}^{a}$

\begin{tabular}{|c|c|c|c|}
\hline$n$ & $-\mathrm{CH}_{3}$ & 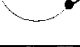 & Difference \\
\hline 1 & 26.2 & 67.0 & +40.8 \\
\hline 3 & 0.0 & 32.7 & +32.7 \\
\hline \multirow[t]{2}{*}{5} & 9.9 & 29.6 & +19.7 \\
\hline & & $<$ & +27.6 \\
\hline
\end{tabular}

${ }^{a}$ Reference 18.

ated when bicyclo[5.1.0]octane is compared with cyclooctane. Puckering should thus be most facile in the homotropylium ion. Moreover, steric effects should favor a puckered cyclohexadienyl ion over a puckered cyclobutenyl ion. Therefore, other factors must be responsible for the different geometries of 1 and 3.

MINDO $/ 3^{20}$ calculations on 1 and 2 are in excellent agreement with the experimental data. ${ }^{10.19}$ For example, the activation barrier of the ring flipping process of 1 was calculated by MINDO $/ 3$ to be $9.8 \mathrm{kcal} / \mathrm{mol}$, only $1.4 \mathrm{kcal} / \mathrm{mol}$ higher than the experimental value. ${ }^{10}$ Therefore, we employed MINDO/ 3 to seek an explanation for the different geometries of 1 and 3 .

The presence of homoaromatic stabilization of $\mathbf{3}$ should be reflected by its $\Delta H_{\mathrm{f}}{ }^{\circ}$ value (Table IV). Since eq 1 is almost thermoneutral, 3 turns out not to be stabilized relative to

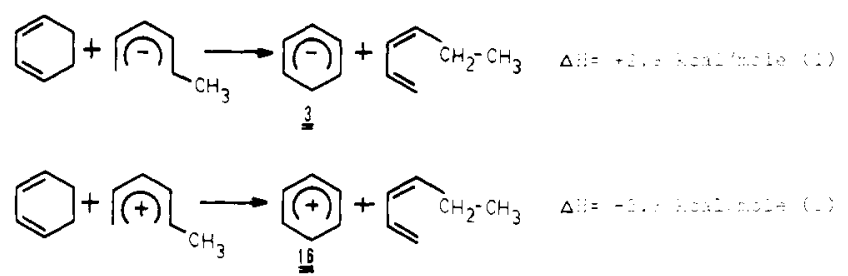

acyclic dienylic anions. Moreover, the potentially antihomoaromatic benzenium ion 16 appears to be even more stabilized (eq 2 ) than the potentially homoaromatic anion 3 . Since positions 1 and 5 of the linear hexadienyl ions cannot interact with each other because of their large distance ( $3.6 \AA$, Table IV), 1,5 overlap cannot play a significant role in the cyclohexadienyl ions either.

In contrast, the large difference between $\Delta H$ of eq 3 and 4

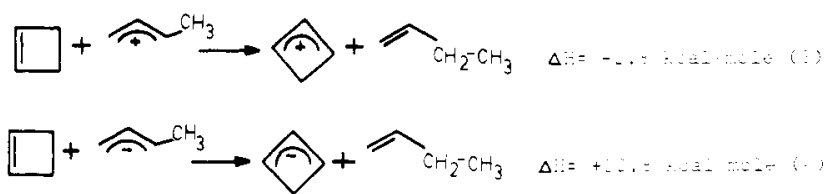

can be explained on the basis of homoaromatic stabilization in the cation and homoantiaromatic destabilization in the anion. However, in spite of the favorable 1,3 interaction, the cyclobutenyl cation is only slightly more stabilized than the 1 -methylallyl cation (eq 3). Even more, eq 5 and 6 show that

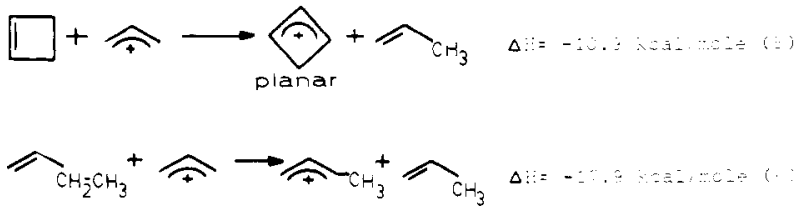

an allylic cation is better stabilized by a methyl group at one $\pi$ terminus than by a methylene group connecting the two termini (in the planar cyclobutenyl cation). Obviously, there must be a second factor, counteracting the homoaromatic stabilization of the cyclobutenyl cation. 
Table IV. Heats of Formation and Geometries of Completely Optimized Structures (MINDO/3) $a, b$

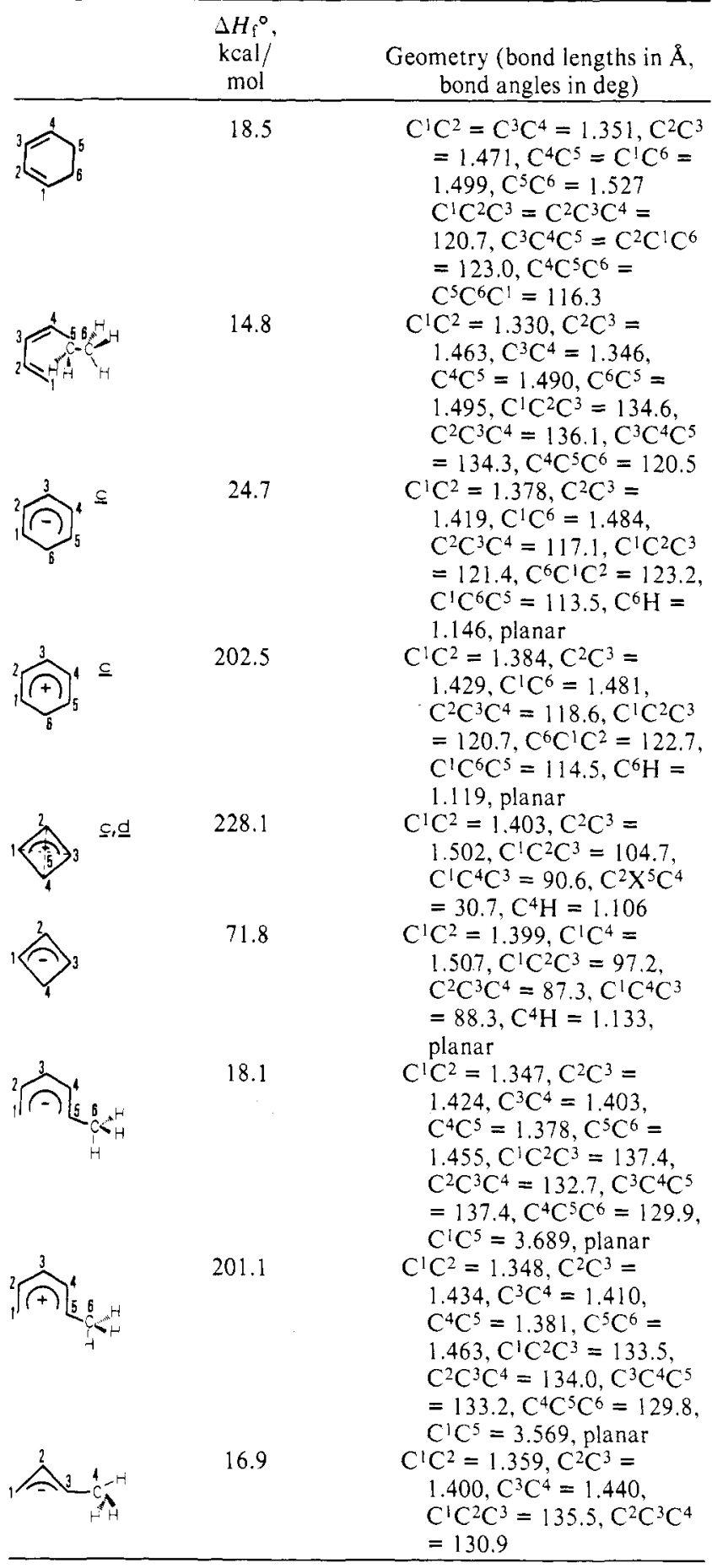

a All data presented in this table are based on complete geometry optimizations. ${ }^{b} \Delta H_{\mathrm{f}}{ }^{\circ}$ for cyclobutene (33.1), 1-butene (1.0), propene (6.5), allyl cation (222.2), and I-methylallyl cation (198.8) were taken from ref 23 . $^{c} C_{s}$ geometry. ${ }^{d}$ Reference 10.

Linear $(4 n+2) \pi$ electron systems are characterized by a symmetric HOMO and an antisymmetric LUMO. The interaction of the LUMO with the orbitals of an intervening $\mathrm{CH}_{2}$ group is symmetry inhibited (Figure 1).22 Therefore, the methylene group of the planar cyclobutenyl cation cannot donate electrons to the allylic system, and relatively low stability results. From Figure 1 it is obvious that the HOMO of the $\pi$ system can interact both with $\pi\left(\mathrm{CH}_{2}\right)$ and with $\pi^{*}$ $\left(\mathrm{CH}_{2}\right)$. The relative importance of these two interactions depends on the energy of the HOMO. In cations with a low-lying

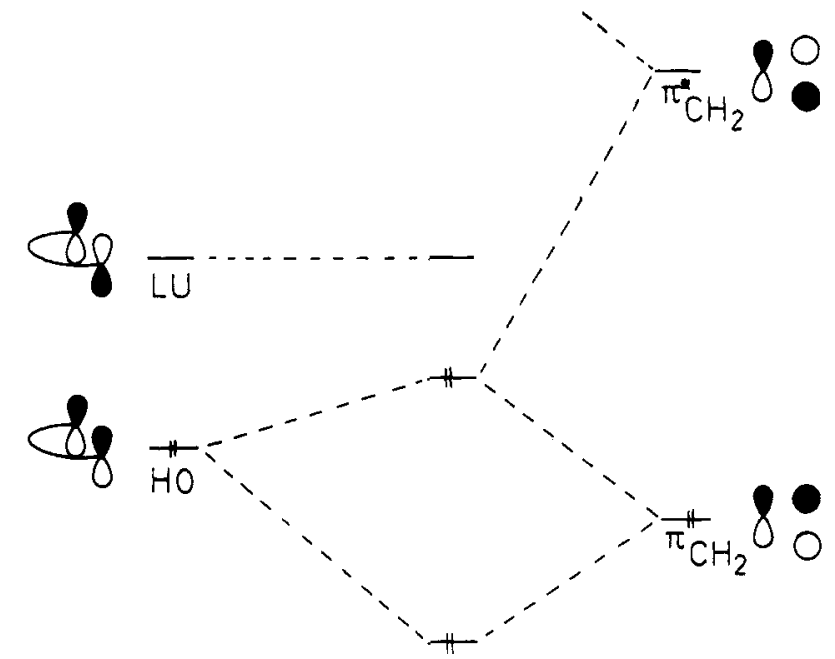

Figure 1. Interaction of linear $(4 n+2) \pi$-electron systems with a methylene group.

Table V. $\pi$-Electron Densities

\begin{tabular}{|c|c|c|c|c|}
\hline & $\overbrace{}^{0.820}$ & $0.994\langle\widehat{\overbrace{}}$ & $0.612\langle\square$ & $\overbrace{0}^{1.557}$ \\
\hline $\begin{array}{l}\text { Total } \pi \text { density } \\
\text { Difference }\end{array}$ & $\begin{array}{c}5.86 \\
-0.14 \mathrm{e}\end{array}$ & $\begin{array}{c}2.01 \\
+0.01 \mathrm{e}\end{array}$ & $\begin{aligned} & 4.16 \\
+ & 0.16 \mathrm{e}\end{aligned}$ & $\begin{array}{c}3.96 \\
-0.04 \mathrm{e}\end{array}$ \\
\hline
\end{tabular}

HOMO, the interaction with $\pi *\left(\mathrm{CH}_{2}\right)$ will be neglegible and the unfavorable $4 \mathrm{e}$ interaction with the filled $\pi\left(\mathrm{CH}_{2}\right)$ will dominate. Puckering will be favorable in these cases since the overlap with $\pi\left(\mathrm{CH}_{2}\right)$ will decrease. In anions, the $\mathrm{HOMO}$ is higher in energy and the stabilizing interaction with $\pi^{*}\left(\mathrm{CH}_{2}\right)$ becomes important, and favors the planar conformation of the ions. These qualitative arguments are supported by the MINDO/ 3 calculations. The HOMO of the planar cyclobu-

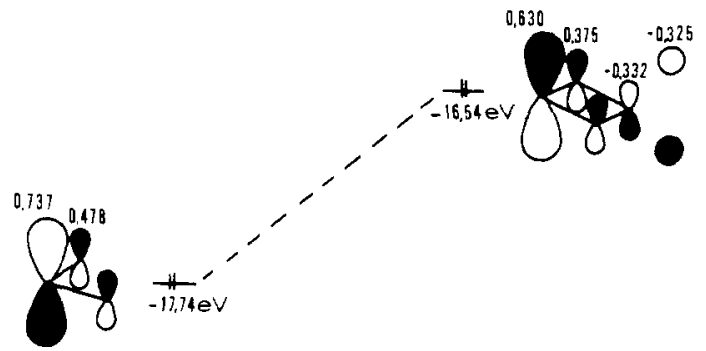

tenyl cation is $1.2 \mathrm{eV}$ higher in energy than that of the allyl cation because $\pi\left(\mathrm{CH}_{2}\right)$ is mixing in in an antiboding fashion.

In the cyclohexadienyl anion, however, the HOMO energy is almost the same as in the pentadienyl anion, indicating that stabilization by $\pi^{*}\left(\mathrm{CH}_{2}\right)$ and destabilization by $\pi\left(\mathrm{CH}_{2}\right)$ cancel. Equal contributions of $\pi$ and $\pi^{*}\left(\mathrm{CH}_{2}\right)$ is also shown

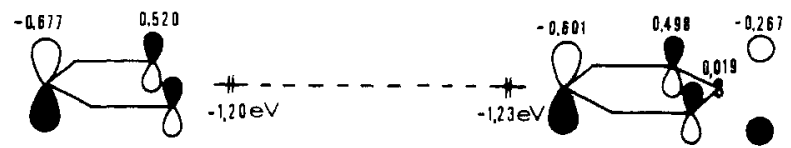

by the zero coefficient at C-6 in the HOMO of the cyclohexadienyl anion. Interaction with the $\mathrm{CH}_{2}$ group, therefore, does not induce nonplanarity as in the case of the cyclobutenyl cation.

This effect is also reflected by the total $\pi$ densities of these ions (Table V). The $\pi$-electron density of the pentadienyl fragment in the cyclohexadienyl anion decreases by 0.14 electrons because of the interaction with the methylene group. On the contrary, the electron density of the allylic fragment 
Table VI. Effect of Puckering on $\Delta H_{\odot}{ }^{\circ}(\mathrm{kcal} / \mathrm{mol}), 1,3(1,5)$ Distances $(\AA)$, and 1,3 $(1,5)$ Bond Indexes of Cyclobutenyl and Cyclohexadienyl Ions ${ }^{a}$

\begin{tabular}{|c|c|c|c|c|c|c|}
\hline & $\Delta H_{\mathrm{f}}{ }^{\circ}$ & $d(1-3)$ & $\rho(1-2)$ & $\Delta H_{f}^{\circ}$ & $d(1-5)$ & $\rho(1-5)$ \\
\hline & Cation & & & Cation & & \\
\hline 0 & 237.9 & 1.95 & 0.274 & 202.5 & 2.49 & 0.056 \\
\hline 10 & 234.0 & 1.83 & 0.308 & & & \\
\hline 20 & 229.8 & 1.78 & 0.338 & 204.4 & 2.50 & 0.058 \\
\hline 30 & 228.1 & 1.74 & 0.372 & & & \\
\hline & Anion & & & Anion & & \\
\hline 0 & 71.8 & 2.09 & 0.213 & 24.7 & 2.48 & 0.056 \\
\hline 10 & 72.1 & 2.10 & 0.208 & 25.3 & 2.48 & 0.056 \\
\hline 20 & 92.9 & 1.70 & 0.628 & 26.9 & 2.47 & 0.056 \\
\hline 30 & & & & 29.7 & 2.46 & 0.058 \\
\hline
\end{tabular}

a MINDO/3 completely optimized geometries.

of the planar cyclobutenyl cation is unaltered by the intervening $\mathrm{CH}_{2}$. Opposite effects are observed in $(4 n) \pi$-electron systems. Linear $(4 n) \pi$-electron cations have a low-lying symmetric LUMO which can interact with $\pi\left(\mathrm{CH}_{2}\right)$. For example, 0.16 electron is donated by $\mathrm{CH}_{2}$ into the pentadienyl system of the benzenium ion. The HOMO of the $4 \pi$-electron cyclobutenyl anion, however, is antisymmetric. Therefore an electron flow into the methylene group is precluded by symmetry.

Geometry optimization with MINDO/3 shows that the planar conformation of the cyclohexadienyl anion corresponds to the energy minimum. This minimum, however, is rather shallow (Table VI). Puckering by $20^{\circ}$ causes an energy increase of only $2.2 \mathrm{kcal} / \mathrm{mol}$; a similar value is obtained for $20^{\circ}$ puckering of the benzenium ion $(1.9 \mathrm{kcal} / \mathrm{mol})$.

In contrast to the similar behavior of the cyclohexadienyl anion and cation, cyclobutenyl ions of opposite charges show large differences. Whereas a $20^{\circ}$ puckering of the cyclobutenyl cation produces a stabilization of $8.1 \mathrm{kcal} / \mathrm{mol}$ (near the stabilization of $9.8 \mathrm{kcal} / \mathrm{mol}$ calculated for the optimum structure), the anion becomes destabilized by $21.1 \mathrm{kcal} / \mathrm{mol}$.

A reason for the almost identical energy increase in the cyclohexadienyl cation and anion is indicated in Table VI. The termini of the $\pi$ systems are separated by almost $2.5 \AA$; consequently, their interaction is very weak. This is shown by the small value of the 1,5-bond index. If the $\mathrm{CH}_{2}$ group is bent upwards, neither the 1,5 distance nor the corresponding bond index is changed significantly. This explains the similar energy increase of the nonplanar cation and anion.

The distances separating $C \cdot 1$ and $C-3$ necessarily are much less in the cyclobutenyl ions. The different 1,3 distances calculated for the cation and the anion as well as the magnitudes of the 1,3-bond indexes indicate remarkably large 1,3 interactions, even in the planar forms. Puckering of the cation increases the 1,3-bonding interaction as atoms 1 and 3 move toward one another. In the anion, puckering should lead to a greater 1,3-antibonding repulsion of termini 1 and 3 and their distance should increase. This is found for a $10^{\circ}$ puckering. At $20^{\circ}$ puckering, however, the destabilization of the system is already so strong that a forbidden orbital crossing occurs (a disrotatory allyl-cyclopropyl anion interconversion is involved)

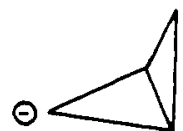

\section{$\underline{20}$}

and the system is better described by the bicyclobutyl anion, 20.

If the large 1,5 distance is also responsible for the absence of homoaromatic overlap in 3 , the system should pucker if the termini are moved closer together. This can easily be tested by calculation. In fact, when a C-1-C-5 distance of $2.0 \AA$ is enforced, the optimized structure is a puckered cyclohexadienyl anion $\left(\varphi=31^{\circ}\right)$ in which the negative charge has decreased on positions 1,3 , and 5 and increased on positions 2 and 4 . This puckering does not have a primarily steric origin; a benzenium cation with carbons 1 and 5 held at the same $2.0 \AA$ distance remains nearly planar $\left(\varphi=8^{\circ}\right)$.

\section{Conclusions}

The general rule that monohomoaromaticity (or monohomoantiaromaticity) is to be expected for systems in which a cyclic array of $4 n+2(4 n)$ electrons is interrupted by one methylene group has to be modified. Although anticipated to be a homoantiaromatic system, the $4 \pi$ cyclohexadienyl cation (protonated benzene) is found to be a stable species. Interaction of $\pi\left(\mathrm{CH}_{2}\right)$ with the symmetric LUMO of the pentadienyl cation (which, in effect, makes it a $6 \pi$ system) is energetically more important than destabilization by 1,5 overlap. Analogously, interaction between $\pi^{*}\left(\mathrm{CH}_{2}\right)$ and the symmetric HOMO of the pentadienyl anion stabilizes the planar structure of the cyclohexadienyl anion so that puckering to a homocyclopentadienyl anion does not occur. If the $\pi\left(\mathrm{CH}_{2}\right)$ electrons are to be counted, the cyclohexadienyl anion would become an $8 \pi$ antiaromatic. The evidence does not support this interpretation.

Goldstein and Hoffmann demonstrated that homoaromaticity should be more important in jons than in neutral compounds. ${ }^{9 a}$ Another restriction is indicated from our work. For electronic reasons, monohomoaromaticity should only be significant in $(4 n+2) \pi$ electron cations (antisymmetric LUMO) whereas monohomoantiaromaticity should be expected for $(4 n) \pi$-electron anions (antisymmetric HOMO). Since steric and ring size effects play an important if not dominating role, simple rules predicting homo(anti)aromaticity do not seem to exist.

\section{Experimental Section}

1,3-Cyclohexadiene (4), 1,4-cyclohexadiene, and 1-methyl-1,4cyclohexadiene (10) were commercially available samples (Chemical Samples Co.). 6-Methyl-1,3-cyclohexadiene was prepared from 4methylcyclohexene (C.S. Co.) according to a procedure previously reported ${ }^{24}$ for the obtention of 1,3-cyclohexadiene from cyclohexene. 6,6-Dimethyl-1,3-cyclohexadiene (7) was prepared from 4,4-dimethylcyclohexene (C. S. Co.) in a similar way. $\mathrm{ND}_{3}$ was prepared from magnesium nitride and heavy water.

Preparation of Carbanions. Potassium metal $(0.30 \mathrm{~g}, 7.7 \mathrm{mmol})$ was dissolved in $\mathrm{NH}_{3}$ or $\mathrm{ND}_{3}(6 \mathrm{~mL})$ and a trace of $\mathrm{Fe}\left(\mathrm{NO}_{3}\right)_{3}$ was added without cooling. When the solution became colorless, the 1,4- or 1,3-diene ( $4 \mathrm{mmol}$ ) was added and the resulting solution was stirred for $3 \mathrm{~h}$ at $-60^{\circ} \mathrm{C}$. All operations were carried out under a nitrogen atmosphere.

Nuclear Magnetic Resonance Spectra. 'H NMR spectra were obtained using either a Varian Associates Model A56/60, HA-100, or HR-300 NMR spectrometer equipped with variable temperature probes. External (capillary) $\mathrm{Me}_{4} \mathrm{Si}$ was used as reference $\left({ }^{1} \mathrm{H}\right.$ and ${ }^{13} \mathrm{C}$ N.MR)

${ }^{13} \mathrm{C}$ NMR spectra were obtained using a Varian Associates Model XL- 100 or a Brucker 270 NMR spectrometer equipped with a broad band decoupler. Fourier transform accessory, and a variable temperature probe. Coupling constants were obtained directly from the ${ }^{13} \mathrm{C}$ NMR spectra in the gyrogate operation mode.

Acknowledgments. We thank Professor Martin Saunders for the use of the Brucker 270 NMR spectrometer at Yale University, and the University of Akron for allowing us to obtain the $300-\mathrm{MHz}$ spectra at their facility. Support by the National Science Foundation, the National Institutes of Health, and the Fonds der Chemischen Industrie is gratefully acknowledged. We also thank the Program of Cultural Co- 
operation between the United States of America and Spain (G.A.) and the Deutsche Forschungsgemeinschaft (H.M.) for fellowships.

\section{References and Notes}

(1) Part 2: G. A. Olah and H. Mayr, J. Org. Chem., 41, 3448 (1976).

(2) (a) University of Southern California; (b) Postdoctoral Research Associate, Case Western Reserve University, 1975-1976; (c) Universität ErlangenNürnberg.

(3) (a) D. E. Applequist and J. D. Roberts, J. Am. Chem. Soc., 78, 4012 (1956); (b) S. Winstein, Q. Rev., Chem. Soc., 23, 141 (1969); Chem. Soc., Spec. Publ., No. 21, 5 (1967); (c) G. A. Olah and P. v. R. Schleyer, Ed., "Carbonium Ions", Vol, III, Wiley-interscience, New York, N.Y., 1972, Chapter 22, p 965; (c) P. R. Story and B. C. Clark, Jr., ibid., Chapter 23, p 1007; (d) P. J. Garratt and M. V. Sargent in "Nonbenzenold Aromatics", Vol. II, J. F. Snyder, Ed., Academic Press, New York, N.Y., 1971, p 208.

(4) G. A. Olah, J. S. Staral, R. J. Spear, and G. Liang, J. Am. Chem. Soc., 97, 5489 (1975)

(5) (a) L. A. Paquette, M. J. Broadhurst, P. Warner, G. A. Olah, and G. Liang, J. Am. Chem. Soc., 95, 3386 (1973); (b) J. F. M. Oth, D. M. Smith, U. Prange, and G. Schröder, Angew. Chem., Int. Ed. Engl., 12, 327 (1973).

(6) See references quoted in R. C. Haddon, J. Am. Chem. Soc., 97, 3608 (1975).

(7) H. Kloosterziel and J. A. A. van Drunen, Recl. Trav. Chim. Pays-Bas, 89, $368(1970)$.

(8) (a) R. B. Bates, S. Brenner, C. M. Cole, E. W. Davidson, G. D. Forsythe, D. A. McCombs, and A. S. Roth, J. Am. Chem. Soc., 95, 926 (1973); (b) R. B. Bates, D. W. Gosselink, and J. A. Kaczynski, Tetrahedron Lett., 205 (1967).
(9) (a) M. J. Goldstein and R. Hoffmann, J. Am. Chem. Soc., 93, 6193 (1971); (b) R. C. Haddon, Tetrahedron Lett., 2797 (1974); (c) R. C. Haddon, J. Am Chem. Soc., 97, 3608 (1975); one review (ref 10) did not include cyclohexadienyl anions as potential homoaromatic species.

(10) W. L. Jorgensen, J. Am. Chem. Soc., 98, 6784 (1976).

(11) (a) H. Spiesecke and W. G. Schneider, Tetrahedron Lett., 468 (1961); (b) J. B. Stothers, "Carbon-13 NMR Spectroscopy", Academic Press, New York, N.Y., 1972, and references cited therein.

(12) D. H O'Brien, A J. Hart and C. R Russell, J Am. Chem Soc. 97, 4410 (1975).

(13) G. A. Olah and H. Mayr, J. Am. Chem. Soc., 98, 7333 (1976).

(14) G. A. Olah and G. Asensio, J. Am. Chem. Soc., submitted for publication.

(15) (a) Allyl cations, see ref 13 and references cited therein; (b) Benzenium ions, G. A. Olah, R. J. Spear, G. Messina, and P. W. Westerman, J. Am. Chem. Soc., 97, 4051 (1975).

(16) G. A. Olah, J. S. Staral, G. Liang, L. A. Paquette, W. P. Melega, and M. J. Carmody, J. Am. Chem. Soc., 99, 3349 (1977)

(17) A comparison of the unsaturated compounds would be more appropriate The few available data for such systems are not very different, however.

(18) S. W. Benson, "Thermochemical Kinetics", and ed, Wiley-Interscience New York, N.Y., 1976.

(19) E. Haselbach and T. Bally, unpublished results.

(20) R. C. Bingham, M. J. S. Dewar, and D. H. Lo, J. Am. Chem. Soc., 97, 1285 (1975).

(21) R. C. Haddon, Tetrahedron Lett., 863 (1975).

(22) J. B. Collins, Ph.D. Thesis, Princeton University, 1975.

(23) R. C. Bingham, M. J. S. Dewar, and D. H. Lo, J. Am. Chem. Soc., 97, 1294 (1975).

(24) Beilstein, "Handbuch der Organischen Chemie", Vol. 5, E II, p 79

\title{
Limitations of Restricted Open-Shell Self-Consistent Field Calculations Applied to Molecules with Multiple Bonds. Electronic Structure and Geometry of the Ground State of HCCN
}

\author{
J. F. Harrison,* A. Dendramis, and G. E. Leroi \\ Contribution from the Department of Chemistry, Michigan State University, \\ East Lansing, Michigan 48824. Received December 21, 1977
}

\begin{abstract}
The restricted open-shell SCF theory predicts the ground state of $\mathrm{HCCN}$ to be a bent triplet carbene, with the nitrene isomer a local minimum on the ground-state surface approximately $8 \mathrm{kcal} / \mathrm{mol}$ above the bent carbene. A modest configuration interaction calculation predicts only one minimum on the ground-state surface and this is neither the carbene $(\mathrm{H}-\mathrm{C}$ $\mathrm{C} \equiv \mathrm{N})$ nor the nitrene $(\mathrm{H}-\mathrm{C} \equiv \mathrm{C}-\mathrm{N})$, but rather the "allene-like" structure, $\mathrm{H}-\mathrm{C}=\mathrm{C}=\mathrm{N}$. Reasons for the qualitatively different predictions of the SCF and $\mathrm{CI}$ theories are discussed.
\end{abstract}

\section{Introduction}

The first spectroscopic observation of the free radical HCCN was by Bernheim et al., ' who, on the basis of the ESR spectrum, concluded that the molecule was a ground-state linear triplet. Subsequent ESR studies by Wasserman et al. ${ }^{2}$ reaffirmed this conclusion. These studies suggest that the structure is $\mathrm{H}-\mathrm{C}-\mathrm{C} \equiv \mathrm{N}$, i.e., linear cyanocarbene. Merer and Travis ${ }^{3}$ attempted to study the UV spectrum of HCCN by generating it in the gas phase via flash photolysis of diazoacetonitrile. The presence of other radicals such as CNC and $\mathrm{CCN}$, which were formed during the photolysis, prevented a successful analysis. Recently Dendramis and Leroi ${ }^{4}$ published a detailed investigation of the infrared spectrum of HCCN and several isotopic modifications, isolated in an inert matrix. These authors were able to fit the observed frequencies with a valence force field characterized by force constants which suggest an allenic structure, $\mathrm{H}-\mathrm{C}=\mathrm{C}=\mathrm{N}$.

In addition, Dendramis and Leroi ${ }^{4}$ observed a band system in the UV between 2400 and $3400 \AA$ which is similar to that attributed to the isoelectronic radical $\mathrm{N}=\mathrm{C}=\mathrm{N}$, again suggesting the allenic structure.
Previous theoretical work pertaining to the geometry and electronic structure is meager. In their classic paper on the carbene structure, Hoffman et al. ${ }^{5}$ reported extended Hückel calculations for HCCN with assumed bond lengths corresponding to the carbene structure, and concluded that the molecule was a linear ground-state triplet. Recently Baird and Taylor ${ }^{6}$ reported ab initio restricted open-shell SCF calculations $^{7}$ in which the geometry of the lowest triplet state was optimized. They predict that the molecule is a bent carbene with a $\mathrm{H}-\mathrm{C}-\mathrm{CN}$ angle of $126^{\circ}$. In a related paper Lucchese and Schaefer ${ }^{8}$ have studied $\mathrm{NC}-\mathrm{C}-\mathrm{CN}$ using the restricted open-shell SCF theory and concluded that this molecule is a bent triplet carbene.

In summary, there are published suggestions that $\mathrm{HCCN}$ is best represented as a linear triplet carbene, $\mathrm{H}-\mathrm{C}-\mathrm{CN}$, a bent triplet carbene,<smiles>[CH]C#[N+]</smiles>

and a linear allene-like triplet, $\mathrm{H}-\mathrm{C}=\mathrm{C}=\mathrm{N}$. We have studied HCCN using the restricted open-shell SCF theory, augmented 